\title{
Laboratory Evaluation for Mitochondrial Dysfunction in Multiple Sclerosis Patients
}

\author{
Kamel Mahmoud Hewedi ${ }^{1}$ MD; Ahmed Fathy Abd-Elaziz ${ }^{2}$ MD ; Ahmed Essmat ${ }^{1, *}$ \\ MD Mohammed Saaed Faheem ${ }^{1}$ MSc
}

*Corresponding Author:

Ahmed Essmat

ahmadesmat81@yahoo.com

Received for publication November 11, 2020; Accepted january 5, 2021; Published online january 5, 2021.

Copyright 2020 The Authors published by Al-Azhar University, Faculty of Medicine, Cairo, Egypt. All rights reserved. This an openaccess article distributed under the legal terms, where it is permissible to download and share the work provided it is properly cited. The work cannot be changed in anyway or used commercially.

doi: 10.21608/aimj.2021.48649.1349

${ }^{I}$ Neurology Department, Faculty of Medicine, Al-Azhar University, Cairo, Egypt.

${ }^{2}$ Clinical Pathology Department, Faculty of Medicine, Al-Azhar University, Cairo, Egypt.

\begin{abstract}
Background: It's though that mitochondrial dysfunction is participated in multiple sclerosis (MS) pathogenesis. Serum lactate and uric acid levels are biochemical markers related to mitochondrial dysfunction.

Aim of work: to assess mitochondrial dysfunction in sufferers with MS through investigating lactate and uric acid serum levels.

Subjects and Methods: This case carried out on 32 patients with MS and 20 safe controls matched by age and sex. Patients have been diagnosed with MS in keeping with McDonald Criteria 2017. Both participants underwent a careful history taking, thorough general and neurological exam and evaluation of serum lactate and uric acid. Using the expanded disability status scale (EDSS), the degree of impairment in sufferers with MS became assessed and fatigue became evaluated the usage of the fatigue severity scale (FSS).

Results: Patients had significantly higher serum lactate levels when relative to controls $(40.7 \pm 18.1$ versus $20.1 \pm 5.8 \mathrm{mg} / \mathrm{dl}$, p=0.001). There were no statistically relevant variations among patients and controls regarding serum uric acid levels $(4.9 \pm 1.1$ versus $5.3 \pm 1.2$ $\mathrm{mg} / \mathrm{dl}, \mathrm{p}=0.337$ ). Correlation analysis showed significantly inverse correlation among levels of serum lactate andEDSS $(r=-0.421, p=0.016)$ and FSS ( $\mathrm{r}=-0.504, \mathrm{p}=0.003)$.

Conclusion: Serum lactate but not serum uric acid is elevated in MSpatients. It was associated with EDSS and FSS.

Keywords: Multiple sclerosis; Serum lactate; Serum uric acid.
\end{abstract}

Disclosure: The authors have no financial interest to declare in relation to the content of this article. The Article Processing Charge was paid for by the authors.

Authorship: All authors have a substantial contribution to the article.

\section{INTRODUCTION}

Multiple sclerosis (MS) is an inflammatory demyelinating and neurodegenerative illness which influences over two million individuals globally and is regarded in several countries to be the main trigger of non-traumatic disabilities in younger adults ${ }^{1}$. MS is thought to be autoimmune pathology, but it is not yet entirely clear the causes for the autoimmune attack on myelin. Mitochondrial disorder and related oxidative strain have a significant position in guiding neurodegeneration, as happens in other chronic neurodegenerative disorders ${ }^{2}$.

Axons in MS lesions incorporate extra mitochondria and an increase in the number of mtDNA removals within the neuronal cell bodies, suggesting that mitochondria are impaired and dysfunctioning. To sustain conduction, demyelinated axons need to consume extra energy. ${ }^{3}$.

Patients with MS have elevated levels of compounds in their cerebrospinal fluid (CSF) and blood derived from the catabolism of ATP (hypoxanthine, xanthine, uric acid, uridine, and creatinine). Such research has firmly endorsed the theory that energy metabolism is impaired in MS patients ${ }^{4}$.

Patients with MS display substantial differences in the circulating concentrations of various metabolites, though it's still uncertain if under this pathological condition, uric acid decreases, increases or does not alter 5 .

It was also shown that brain lactate is formed by anaerobic neuron glycolysis and astrocytes under normal homeostatic conditions to meet acutely increased energy requirements ${ }^{6}$.Evaluation of the serum specimens of MS sufferers displayed increased lactate level in the majority of samples compared with controls. Sign of elevated glycolysis in MS because of mitochondrial dysfunction was strengthened by a link among the number of inflammatory plaques and lactate concentration ${ }^{7}$. The present study was designed to assess mitochondrial dysfunction in MS patients. by investigating lactate and uric acid serum levels. 


\section{Subjects AND MATERIALS}

At Al-Azhar University Hospitals, Cairo, Egypt, this case control study was conducted. The local Ethics Committee accepted the examine procedure and the knowledgeable consent of all participants were approved. The research included 32 patients with MS and 20 safe controls matched by age and sex. Patients have been diagnosed with MS as per McDonald's Revised Criteria $2015^{8}$.Patients were excluded from the study if they had associated conditions affecting serum lactate (body-building exercises, muscle diseases, renal dysfunction, epilepsy, hepatic failure, uncontrolled diabetes mellitus, malignancy or mitochondriotoxic drugs or substances e.g.: alcohol, cocaine, linezolid, metformin, acetaminophen, beta 2 agonists and theophylline) or uric acid (hypothyroidism, hyperthyroidism, Wilson's disease, obesity, psoriasis or use of diuretic medications or uricosurics) levels.

Careful history taking, thorough general and neurological examination and laboratory investigation (CBC, ALT, AST, albumin, urea, creatinine, RBS, serum lactate and uric acid) were carried out by all participants. The degree of disability in sufferers with MS became evaluated the usage of the expanded disability status scale (EDSS) [9] and fatigue became assessed using the fatigue severity scale (FSS) ${ }^{9}$.

Data obtained from the present study were statistically analyzed using SPSS 22 (IBM, USA). Compared to the $t$ test, numerical data were expressed as mean \pm standard deviation and the number and percentage of categorical data were represented and compared with the exact Fisher test. Using Pearson's correlation coefficient, correlation became achieved among numerical values.

\section{RESULTS}

The present case control study involved 32 patients with MS and 20 controls matched by age and sex (Table1). The studied patients comprised 27 patients $(84.4 \%)$ with relapsing-remitting MS (RRMS) and 5 patients $(15.6 \%)$ with secondary progressive MS (SPMS) (Table 2).Patients received significantly higher serum lactate levels relative to controls $(40.7 \pm$ 18.1 versus $20.1 \pm 5.8 \mathrm{mg} / \mathrm{dl}, \mathrm{p}=0.001)$. There were no statistically relevant variations among patients

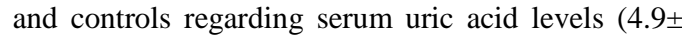
1.1 versus $5.3 \pm 1.2 \mathrm{mg} / \mathrm{dl}, \mathrm{p}=0.337$ ) (Table1). No substantial variations were noted among RRMS and SPMS patients regarding serum lactate and uric acid levels. Correlation analysis showed significantly inverse correlation between serum lactate levels and both EDSS $(r=-0.421, p=0.016)$ and FSS $(r=-0.504$, $\mathrm{p}=0.003)($ Table3).

\begin{tabular}{|c|c|c|c||}
\hline & Patients & Controls & $\begin{array}{c}\text { P } \\
\text { value }\end{array}$ \\
\hline $\begin{array}{c}\text { Age (years) mean } \\
\pm \text { SD }\end{array}$ & $\begin{array}{c}33.5 \pm \\
8.7\end{array}$ & $\begin{array}{c}30.9 \pm \\
4.5\end{array}$ & 0.22 \\
\hline Male/Female n & $15 / 17$ & $10 / 10$ & 0.83 \\
\hline $\begin{array}{c}\text { Serum lactate } \\
(\mathrm{mg} / \mathrm{dl}) \text { mean } \pm \text { SD }\end{array}$ & $\begin{array}{c}40.7 \pm \\
18.1\end{array}$ & $\begin{array}{c}20.1 \pm \\
5.8\end{array}$ & 0.001 \\
\hline $\begin{array}{c}\text { Serum uric acid } \\
(\mathrm{mg} / \mathrm{dl}) \text { mean } \pm \text { SD }\end{array}$ & $4.9 \pm 1.1$ & $5.3 \pm 1.2$ & 0.337 \\
\hline \hline
\end{tabular}

Table 1: Demographic and laboratory data in patients and controls.

\begin{tabular}{||c|c||}
\hline \multicolumn{2}{|c|}{ Disease type $\mathrm{n}(\%)$} \\
\hline Relapsing-remitting & $27(84.4)$ \\
\hline Secondary progressive & $5(15.6)$ \\
\hline Disease duration (years) mean \pm SD & $5.04 \pm 3.6$ \\
\hline Number of lesions (n) mean \pm SD & $4.09 \pm 3.4$ \\
\hline EDSS mean \pm SD & $2.8 \pm 1.9$ \\
\hline FSS mean \pm SD & $4.2 \pm 1.4$ \\
\hline
\end{tabular}

EDSS: Expanded Disability Status Scale, FSS: Fatigue Severity Scale

Table 2: Clinical data in the studied patients

\begin{tabular}{|c|c|c|c|c|}
\hline \multirow{2}{*}{} & \multicolumn{2}{|c|}{ Lactate } & \multicolumn{2}{c|}{ Uric acid } \\
\cline { 2 - 5 } & $\mathbf{r}$ & $\mathbf{p}$ & $\mathbf{r}$ & $\mathbf{p}$ \\
\hline $\begin{array}{c}\text { Disease } \\
\text { duration }\end{array}$ & $\begin{array}{c}- \\
0.139\end{array}$ & 0.634 & $\begin{array}{c}- \\
0.087\end{array}$ & 0.449 \\
\hline $\begin{array}{c}\text { Number of } \\
\text { attacks }\end{array}$ & $\begin{array}{c}- \\
\text { EDSS }\end{array}$ & 0.178 & $\begin{array}{c}- \\
0.097\end{array}$ & 0.596 \\
\hline FSS & -0.504 & 0.003 & 0.001 & 0.998 \\
\hline \hline
\end{tabular}

Table 3: Correlation between lactate and uric acid levels and the clinical data

\section{DISCUSSION}

The current research showed elevated serum lactate levels in patients with MS as relative to 20 normal healthy controls. Thisresult can confirm the theory that mitochondrial impairment plays a significant position in MS pathogenesis and is particularly relevant to the disease's neurodegenerative phase. Our results are supported by Hassan and Mehaney ${ }^{10}$. In their work, MS patients had substantially higher lactate serum levels alongside lower UA serum levels as compared to healthy controls. Our findings are also supported by the Amorini, Nociti ${ }^{7}$ who reported thatserum lactate levels in MS patients were three 
times higher than in healthy controls. Interestingly, the study of Albanese, Zagaglia ${ }^{6}$ showed that lactate was better in patients' cerebrospinal fluid than in controls.

In comparison, our present study demonstrated no statistically substantial variations amongserum UA levels in MS patients as compared to healthful controls. These finding ssupported by the study of Gosch, Davis ${ }^{11}$ in which 499 MS patients were relative to 276 healthy controls. Similar conclusions were reported by Kohansal, Farahani ${ }^{12}$.Of note,Massa, O'reilly ${ }^{13}$ prospective study found a tendency towards a reduced risk of MS between people with higher serum uric acid;however the association become now no longer significant. In another work, Uric acid serum level shave been assessed in sixty sufferers with MS without relapse throughout the last three months and thirty healthy controls with no significant differences among groups $^{14}$.

In contrast to our study,Ashtari, Bahar ${ }^{15}$ on 130 RRMS patients and 50 controls observed substantially decreaselevels of uric acid in MS sufferers with relapsing disease in comparison to those with remitting disease and controls. Moreover,Liu, Shen ${ }^{16}$ discovered that serum UA levels had decrease in MS sufferers relative to healthful controls and different neurological inflammatory diseases.

On the other hand,an increase in circulating uric acid and other oxypurines(xanthine and hypoxanthine) as well as $\beta$-pseudouridine and uridine was observed for patients with MS in another study that included 170 MS patients and 163 healthy controls.Concomitant rises in circulating creatinine, malondialdehyde, nitrite and nitrate and reductions in ascorbic acid suggest that MS causes changes in the metabolism of energy and balance of oxidants / antioxidants which may be controlled within the serum of patients with $\mathrm{MS}^{17}$.

\section{CONCLUSION}

According to our study and in the previous studies, lactate levels are elevated in both serum and CSF in patients with MS, but its role as a potential biomarker for the disease progression and activity is still controversial and further studies should be encouraged for better exploration of the importance of lactate serum levels and of its variations in relation to the course of the disease and disability progression.

\section{REFERENCES}

1. Heydarpour P, Khoshkish S, Abtahi S, et al. Multiple Sclerosis Epidemiology in Middle East and North Africa: A Systematic Review and Meta-Analysis. Neuroepidemiology 2015; 44: 232-44. 2015/06/20. DOI: $10.1159 / 000431042$.

2. Mahad DH, Trapp BD and Lassmann H. Pathological mechanisms in progressive multiple sclerosis. The Lancet Neurology 2015; 14: 183-93.
3. Trapp BD and Stys PK. Virtual hypoxia and chronic necrosis of demyelinated axons in multiple sclerosis. The Lancet Neurology 2009; 8: 280-91.

4. Amorini AM, Petzold A, Tavazzi B, et al. Increase of uric acid and purine compounds in biological fluids of multiple sclerosis patients. Clinical Biochemistry 2009; 42: 1001-6.

5. Sotgiu S, Pugliatti M, Sanna A, et al. Serum uric acid and multiple sclerosis. Neurological Sciences 2002; 23: $183-8$.

6. Albanese $\mathrm{M}$, Zagaglia S, Landi $\mathrm{D}$, et al. Cerebrospinal fluid lactate is associated with multiple sclerosis disease progression. Journal of neuroinflammation 2016; 13: 1-7.

7. Amorini AM, Nociti V, Petzold A, et al. Serum lactate as a novel potential biomarker in multiple sclerosis. Biochimica et Biophysica Acta (BBA)Molecular Basis of Disease 2014; 1842: 1137-43.

8. Polman $\mathrm{CH}$, Reingold SC, Banwell B, et al. Diagnostic criteria for multiple sclerosis: 2010 revisions to the McDonald criteria. Annals of neurology 2011; 69: 292-302.

9. Krupp LB, Alvarez LA, LaRocca NG, et al. Fatigue in multiple sclerosis. Archives of neurology 1988; 45: 435-7.

10. Hassan A and Mehaney D. Serum lactate and uric acid as biomarkers for disease activity and progression in multiple sclerosis. Egyp J Neur, Psy Neuros 2015; 52: 127-31.

11. Gosch AA, Davis MF and Denny JC. Uric Acid Levels in Relation to Progression of Multiple Sclerosis. 2016.

12. Kohansal M, Farahani H and Faraji F. Assessment of changes in biochemical parameters associated with kidney function in patients with multiple sclerosis while taking the drug. Journal of Shahrekord Uuniversity of Medical Sciences 2016; 18.

13. Massa J, O'reilly E, Munger KL, et al. Serum uric acid and risk of multiple sclerosis. Journal of neurology 2009; 256: 1643-8.

14. Mostert JP, Ramsaransing GSM, Heersema DJ, et al. Serum uric acid levels and leukocyte nitric oxide production in multiple sclerosis patients outside relapses. Journal of the neurological sciences 2005; 231: 41-4.

15. Ashtari F, Bahar M, Aghaei M, et al. Serum uric acid level in patients with relapsing-remitting multiple sclerosis. J Clin Neurosci 2013; 20: 676-678. 2013/03/27. DOI: 10.1016/j.jocn.2012.05.054.

16. Liu B, Shen Y, Xiao K, et al. Serum uric acid levels in patients with multiple sclerosis: a meta-analysis. Neurological research 2012; 34: 163-71.

17. Amorini AM, Petzold A, Tavazzi B, et al. Increase of uric acid and purine compounds in biological fluids of multiple sclerosis patients. Clin Biochem 2009; 42: 1001-6.2009/04/04.DOI: 10.1016/j.clinbiochem.2009.03.020. 